\title{
IS-LM Paradigm in Macroeconomics: A Survey and Evaluation
}

\author{
Haiming $\mathrm{Li}^{1}$, Xiao $\mathrm{Wu}^{2}$ \\ ${ }^{1}$ College of Economics and Management, Southwest University, Chongqing, China \\ ${ }^{2}$ Department of Business Administration, Chongqing College of Finance and Economics, Chongqing, China \\ Email: Ihm2@sina.com, 670734713@qq.com
}

Received 25 March 2015; accepted 19 April 2015; published 22 April 2015

Copyright (C) 2015 by authors and Scientific Research Publishing Inc.

This work is licensed under the Creative Commons Attribution International License (CC BY). http://creativecommons.org/licenses/by/4.0/

(c) (7) Open Access

\section{Abstract}

This paper analyzes many serious defects existing in traditional aggregate demand/aggregate supply paradigm based on IS-LM model. Those defects cause the situation that IS-LM model declines gradually, but it is still not dead, and continuously revives through modification. This paper distinguishes from rounds of modification on traditional aggregate demand/aggregate supply paradigm. The first round of modification was just introducing the dynamic ad hoc IS-LM model of rational expectation which started from the end of 1970 s and the beginning of 1980s. Because the micro-foundation problems are not solved and the rational expectation carries out extreme judgment on monetary neutrality and ineffectiveness of macroeconomic policy, the first modification fails to realize big success. The second round of modification is just happening; through introducing rational expectation and New Phillips Curve (NPC), the powerful improvement has been made in micro-foundation, dynamic form, and monetary policy rules, and the model is called IS-LM/ MP-NPC model. This paper also points out some limitations which are not solved in the second modification.

\section{Keywords}

IS-LM Paradigm, Rational Expectationis-LM Model, IS-LM(MP)-NPC Model

\section{Introduction}

The core of traditional macroeconomics theory and policy practice can be expressed as aggregate demand/aggregate supply (AD-AS) paradigm based on IS-LM model. For example, Dornbusch and Fischer (p. 100) [1] call IS-LM model "core of modern macroeconomics". Patinkin considers it is "central message" of Keynes (p. 1) [2]. Solow (p. 14) [3] calls it "the trained intuition" of economists. 
Therefore, IS-LM model once occupied the dominant position of macroeconomics and became a general frame for economists to discuss macroeconomic policy. The development of macroeconomics in the 20th century can be regarded as a process where IS-LM models emerged, declined and revived. In the period, many important events of economic thought history happened, such as Keynesian revolution, rational expectation revolution and popular dynamic general equilibrium model.

For a long time, textbooks are inundated with all kinds of IS-LM graphs. Scholars are high on using the simple movement of IS and LM curves to analyze economic policy and predict economic behaviors, although such method is seriously criticized by many scholars—Lucas Critique [4] pushes these criticisms to the peak. In the end of 1970s and early 1980s, rational expectation and dynamics were introduced into the IS-LM model. This represents the first round of modification under the introspection, but it is just a flash in the pan. In late 1990s, with the help of dynamic general equilibrium approach, neoclassical synthesis made IS-LM model revive in the optimal form. This is the second round of modification. This paper evaluates traditional IS-LM model, modification process and future evolution trend.

\section{Traditional IS-LM Paradigm and Its Defects}

Traditional IS-LM model provides a simple frame to analyze the interactions of product market and monetary market in deciding national income. The model focuses on effects of interest rate on connecting two markets. A representative linear model is as follows [5]:

$$
\begin{gathered}
\ln y=a_{0}-a_{1} r, \quad a_{1}>0 \quad \text { (IS curve) } \\
\ln M-\ln P=b_{0}+b_{1} R-b_{2} \ln y, \quad b_{1}, b_{2}>0 \quad \text { (LM curve) } \\
\ln y-\ln y^{*}=c_{0}+c_{1} \pi, \quad c_{1}>0 \quad \text { (Phillips curve/AS curve) }
\end{gathered}
$$

where, $y$ is actual output; $y^{*}$ is potential output; $P$ is price level in current period; $P_{-1}$ is price level in last period; $\pi=\ln P-\ln P_{-1}$ is inflation rate; actual rate $r$ and nominal interest rate $R$ are connected through Fisher relationship: $r \approx R-\pi . M$ is exogenous Money Supply.

The above relationship actually contains two-step method of traditional IS-LM model: the first step is output-actual interest rate two-dimensional space $(y, r)$ Hicks model under Keynes's fixed pricehypothesis. In this mode, price and currency supply become exogenous variables which can be expressed with the first two equations. This is the thought in Keynes's short-term analysis, i.e. demand decides output. The second step is outputprice two-dimensional space $(y, P)$ or output-nominal interest rate-price three-dimensional space $(y, R, P)$ neoclassical synthesis aggregate supply-aggregate demand (AS-AD) model under variable price hypothesis. After variable price is introduced, the Phillips curve is needed to close the model. The Phillips curve indicates deviation of actual output from potential output is in positive correlation with inflation rate. It actually reflects supply relationship of economic system.

Traditional model has the following functions:

Firstly, teaching function. It is the simplest model to analyze general equilibrium relationship between actual economy department and currency department. Besides, the above graph can make implication of economic analysis and policy analysis visualized and can bring convenience for discussing monetary policy, fiscal policy and their interactions. Thus, macroeconomists and vast public (reporters and officials etc.) can exchange more easily. Colander [6] holds that IS-LM model owns proper mathematics degree. Geometric graphs it provides have superiority in terms of judging the right and wrong, detecting and grading students. So, the IS-LM model has high benefit/cost ratio.

Secondly, theoretical explanation function. IS-LM model can clarify the interpretation of a macroeconomic theory through comparing other theories, [7] so it becomes the common foundation of classical economics, Keynesianism, new classical macroeconomics and new Keynesianism etc.

Thirdly, explanations of policy. IS-LM model can represent, explain or predict performance of an economy. Thus, some simplified econometric models of non-aggregate macroeconomics used by government and enterprises for policy evaluation and economic prediction is developed. It is used to select the best policy scheme in certain period, so these models are widely applied in the actual economic analysis.

However, traditional IS-LM model is attacked violently by a large number of scholars. Violent disputes and researches show it has the following fundamental and fatal flaws: 
Firstly, lack of micro-foundation. It simplifies complex economy to several rough aggregate equations by ad hoc hypothesis. These relations are not deduced through optimization of rational agent. According to Lucas critique, the function represented by IS and LM curves does not keep unchanged when economic policy changes, so policy judgment of the model is unreliable.

Secondly, short-term static nature. Changes in wage, price and money stock are considered as exogenous. Because dynamic characteristic is hidden in the stability of equilibrium, dynamic structure of economy plays no role in the process of deciding convergence. Chick [8] called it "pseudo dynamics of IS-LM". IS-LM model does not introduce hysteresis effect of time and economy variables, so it is necessary to replace IS-LM model with dynamic time series analysis.

Thirdly, inconsistent logic. IS curve as flow equilibrium is inconsistent with LM curve as stock equilibrium. As a result, savings will make wealth stock change, thus influencing position of LM curve. Equilibrium of IS and LM cannot be maintained. The solutions are as follows: make the time long enough to achieve complete adjustment; or make the time short enough to ignore stock changes. This limits analysis ability of the model.

Fourthly, functional defect. Romer [9] indicates when interest rate is used as the operation objective, IS-LM cannot handle monetary policy problem. Walsh [10] holds that it cannot be well applicable to inflation target inganalysis. Now the position of effectiveness problem of fiscal policy and monetary policy as macroeconomics center discussed with IS-LM has declined in short-term fluctuation analysis. Money supply as the target of central bank in the past now no longer becomes the target.

Fifthly, teaching and research divergence. IS-LM model prevails in primary and intermediate text, while advanced text and macroeconomic study front widely apply dynamic (stochastic) general equilibrium model. They have great differences in fundamental assumption and modeling thought.

It is just these factors that lead to gradual decline of IS-LM model. Most macroeconomic theories and empirical researches no longer use IS-LM model. IS-LM model sometimes appears in macroeconomics text, but it just serves as a ladder to construct aggregate demand curve in aggregate supply-aggregate demand model.

Even so, IS-LM is not still dead. Criticisms of numerous defects of traditional IS-LM model fail to shake its central role and teaching tool position in macroeconomics. This is mainly because we cannot find out a more powerful analysis tool to understand short-term economic fluctuations. Hence, overcoming these defects becomes modification of traditional IS-LM model. Such modification process started from the end of 1970s and early 1980s. The thought was to combine popular rational expectation to make IS-LM model become dynamic model. This is the first round of modification. Since late 1990s, neoclassical synthesis made traditional IS-LM model revive with the help of its expansion form-optimizing IS-LM model. This is the second round of modification.

\section{Dynamic ad Hoc IS-LM Model with Rational Expectation}

In this round of modification, rational expectation hypothesis is introduced in IS-LM model, and it is made dynamic, such as Sargent-Wallace model [11], and Blanchard Model [12]. Basic mode is as follows:

$$
\begin{gathered}
\ln y_{t}=a_{0}-a_{1} r_{t}, \quad a_{1}>0 \quad \text { (IS curve) } \\
\ln M_{t}-\ln P_{t}=b_{0}+b_{1} R_{t}-b_{2} \ln y_{t}, \quad b_{1}, b_{2}>0 \quad \text { (LM curve) } \\
\ln y_{t}-\ln y_{t}^{*}=c_{0}+c_{1}\left(\ln P_{t}-E_{t-1} \ln P_{t}\right), \quad c_{1}>0 \quad \text { (Lucas AS curve) }
\end{gathered}
$$

where, $E_{t-1} \ln P_{t}$ represents price level of rational expectation at t which forms at $t-1, r_{t} \approx R_{t}-E_{t} \pi_{t+1}$.

Compared with traditional model, this model specifically introduces rational expectation. Lucas aggregate supply curve replaces the Phillips curve. In fact, Lucas AS curve is the Phillips curve with rational expectation. This is because $\ln P_{t}-E_{t-1} \ln P_{t}=\pi_{t}-E_{t-1} \pi_{t}$.

The significant result of the model is so-called policy ineffectiveness proposition (PIP). Under the condition of rational expectation, the mean value of individual prediction error $\ln P_{t}-E_{t-1} \ln P_{t}$ will be zero. Economy is always on the natural rate or potential output $y_{t}^{*}$. Only unexpected monetary policy can influence economic fluctuations. Expected monetary policy can only result in expected inflation. Regardless of long term or short term, it will not influence real economic activities. This result actually repeats classical monetary neutrality and liberalism economic policy.

Rational expectation IS-LM fails to be widely accepted due to three causes. Firstly, some economists (espe- 
cially macroeconomic theorists) consider it lacks micro-foundation and thus lacks behavior consistency. However, consistent logic should be the inevitable result of optimization and expected behavior, so it is the core of dynamic economic theory. Secondly, other scholars and especially applied economists doubt this model, because this model considers output is not series correlation to deviation of potential productivity. Thirdly, many (including economists of central bank) believe systematic selection of monetary authority imposes great influence on economic fluctuations and refuses "policy ineffectivenes" significance of the model.

\section{The Second Round of Modification of Traditional IS-LM Model}

Since late 1990s, traditional IS-LM model has improved greatly, for example, [13]-[18]. There are two representative models: IS-LM-NPC and IS-MP-NPC. Here, MP refers to macroeconomic policy curve, and NPC refers to new Phillips curve. The former provides micro-foundation based on individual rational expectation hypothesis for aggregate relationship of IS-LM model, and highlights family and enterprise optimization problem, also called optimizing IS-LM model; the latter holds simplification of macro-economic model and cancels LM curve. Although the latter model has no obvious micro-foundation, setting of behavior relationship is basicallyconsistent with equilibrium result of the former model. These basic relations are as below:

$$
\begin{gathered}
\ln y_{t}=a_{0}-a_{1} r_{t}+E_{t} \ln y_{t+1}, \quad a_{1}>0 \quad \text { (IS curve) } \\
\ln M_{t}-\ln P_{t}=b_{0}+b_{1} \ln y_{t}-b_{2} R_{t}, \quad b_{1}, b_{2}>0 \quad \text { (LM curve) } \\
\ln y_{t}-\ln y_{t}^{*}=c_{0}+c_{1}\left(\pi_{t}-\beta \pi_{t}^{e}\right), \quad c_{1}, \beta>0 \quad \text { (new Phillips curve/AS curve) } \\
R_{t}=\mu_{0}+\pi_{t}^{e}+\mu_{1}\left(\pi_{t}-\bar{\pi}\right)+\mu_{2}\left(\ln y_{t}-\ln y_{t}^{*}\right), \quad \mu_{1}, \mu_{2}>0 \quad \text { (Taylor rule) }
\end{gathered}
$$

IS curve is still downward sloping. On the one hand, current real output is positive correlation with expected future real output, which reflects forward expectation; on the other hand, it is negative correlation with real interest rate. The rise in real interest rate will reduce investment demand and consumer demand, and the output will be below potential level.

LM curve has no essential change. It still indicates that the demand for real currency balance is positive correlation with real income and negative correlation with nominal interest rate (so, real interest rate).

New Phillips curve shows when actual inflation rate exceeds the expected inflation rate $\pi_{t}^{e}$, real output will increase above the potential level. Usually, there are two methods for expected setting: adaptive expectation $\pi_{t}^{e}=\pi_{t-1}$ or rational expectation $\pi_{t}^{e}=E_{t} \pi_{t+1}$. IS-MP-NPC model does not stress expectation must be rational expectation, while IS-LM-NPC model adopts rational expectation assumption. Different from Sargent-Wallace model, rational expectation adopts forward expectation form. The parameter $\beta$ reflects replacement between output and unemployment. If $\beta=1$, new Phillips curve will degrade to old Phillips curve or Lucas AS curve. Under rational expectation hypothesis, output and unemployment have no long-term replacement relationship. Usually, $0<\beta<1$, even in a long term, output and unemployment have replacement relationship.

Finally, there is still the last variable needed to be explained, i.e. money supply. In traditional model, it is operation target of monetary policy, but in the new model, money stock is an endogenous variable which depends on money demand. Price level also becomes an endogenous variable which is influenced by exogenous impact and monetary policy rules. Thus, we need a monetary policy rule to close the model. Supposing operation target of monetary policy is nominal interest rate, central bank may use inflation targeting rule to decide nominal interest rate. In other words, all information available is utilized to confirm optimal interest rate according to the loss function including target inflation and output concern degree of central bank.

A simpler method in practice is that, we don't utilize all information, and only a part of information may be used to observe relevant information of variables and confirm nominal interest rate in line with experience and skills of monetary policymakers. Such method is applied in most industrialized countries currently. It is well described by above rule. Taylor rule indicates nominal interest rate makes response to deviation of output gap and inflation from target inflation: when real output is greater than potential output and actual inflation rate is larger than target inflation rate $\bar{\pi}$, central bank will increase nominal interest rate. The parameters $\mu_{1}$ and $\mu_{2}$ show when real output or inflation rate alters, how much the interest rate $R_{t}$ set by central bank will change.

In fact, Taylor rule amends the Fisher equation. For long-term equilibrium, $y_{t}=y_{t}^{*}, \pi_{t}^{e}=0$ and $\pi_{t}=\bar{\pi}$. Then, we get an equilibrium nominal interest rate $R_{t}^{*}=\mu_{0}$, which is also equilibrium real interest rate. Then, 
$R_{t}=R_{t}^{*}+\pi_{t}^{e}$. So nominal interest rate is equal to real interest rate plus expected inflation rate. Since this relation depends on $\pi_{t}=\bar{\pi}$, this indicates target inflation rate will decide inflation expectation under long-term equilibrium state.

IS-LM-NPC model indulges in establishing micro-foundation for the above aggregate relation. For example, Dynamic Stochastic General Equilibrium (DSGE) is used to maximize the discounted sum of future expected utility under social resource constraint condition so as to get IS and LM equations. By rational expectation, New Phillips curve is obtained from optimal price adjustment behavior of monopolistic competition firms. This curve has micro-foundation of sticky price, which is consistent with monetary transmission mechanism. In the literature, new Phillips curve is also called price adjustment (PA) equation.

Such optimizing IS-LM model provides insight for effects of economic policy on macroeconomic variable and can easily combine econometrics or calibration technique for estimation, so it has become a baseline model of monetary policy, economic fluctuation and welfare analysis.

However, Romer [9], Bofinger et al. [19] [20] consider macroeconomic model based on micro-foundation is more complex. But it is not superior to traditional ad hoc macroeconomic model in terms of explanation function. Different from the above model, IS-MP-NPC model considers LM curve is redundant.

IS-MP-NPC model still follows aggregate supply-aggregate demand method. Taylor rule may be described with monetary policy upward sloping, which called Macroeconomic Policy (MP) curve. Its function is similar to LM curve. Then, IS-LM curve can form an aggregate demand-inflation (ADI) curve. In combination of new Phillips curve (NPC), we can build a new aggregate supply-demand model. This model can be called IS-MPNPC or ADI-NPC model.

\section{Defects in the Second Round of Modification}

It should be said that great breakthrough has been made in the second round of modification on traditional model. This modification is still based on rational expectation, but it further highlights the optimization problem of families and firms. Thus, optimizing IS curve and optimizing LM curve are elicited to represent aggregate demand of macroeconomics. Meanwhile, new Phillips curve is obtained from optimizing price adjustment behaviors of more realistic monopolistic competition firms to represent the supply of an economy. Obviously, the new model owns accepted micro-foundation.

Of course, optimizing IS-LM model often owns more complex mathematic form. We also point out another widely accepted opinion. Like traditional IS-LM model, it advocates simplification of macro-economic model and omits micro-foundation of IS-LM. More uniquely, it takes into account of operation target of central bank which regards interest rate as monetary policy, and cancels traditional LM curve. Thus, IS-LM model without LM curve is established. It is interesting that most forms of this model are similar to optimizing IS-LM model.

We compare IS-LM model discussed in this paper as follows: (Table 1).

Compared with traditional model, is improvement of new model successful?

The new model is often proud of "micro-foundation". IS-LM-NPC model is consistent with intertemporal optimization behaviors of rational agent and owns micro-foundation factors that old Keynesianism (and traditional model) lacks: price adjustment cost, asynchronism of price adjustment, forward expected price setting and monopolistic competition. Price level has been endogenous. It is an endogenous variable influenced by exogenous impact and monetary policy rule. In combination of money supply rule, even for short-term stickiness of individual price, price level will make response to exogenous lasting changes of money stock in both short term and long term.

Parameters of new model come from utility function, production function and structure parameters in price adjustment process. Both demand and supply fully consider effects of policy changes on expectations of rational agent. Thus, the new model declares it can suffer Lucas critique. Due to microeconomic foundation, it closely combines policy analysis with individual welfare (utility). This makes research literature to discuss the decision of macro-economic activities monetary policy design with it rise increasingly.

However, just as Lucas critique criticizes traditional macroeconomic behavior equation is ad hoc. The hypothesis of representative agent for individual preference and technology is also ad hoc. Nobody has reason to think these parameters will keep unchanged when policy rules change. In fact, individual basic characteristic is in system, culture and social environment. These factors impose great influence on preference and technical parameters. Arbitrarily supposing these parameters are not changed is not a proper practice. From this perspective, 
Table 1. Five kinds of IS-LM model.

\begin{tabular}{|c|c|c|c|c|}
\hline & Basic equations of model & $\begin{array}{l}\text { Equation } \\
\text { source }\end{array}$ & $\begin{array}{l}\text { Intermediate } \\
\text { target of } \\
\text { monetary } \\
\text { policy }\end{array}$ & Policy conclusion \\
\hline $\begin{array}{l}\text { Hicks } \\
\text { model }\end{array}$ & $\begin{array}{l}\ln y=a_{0}-a_{1} r \quad \text { (IS) } \\
\ln \bar{M}=b_{0}+b_{1} r-b_{2} \ln y \quad(\mathrm{LM})\end{array}$ & ad hoc & Money supply & $\begin{array}{l}\text { Short-term demand } \\
\text { management } \\
\text { Policy effectiveness }\end{array}$ \\
\hline $\begin{array}{l}\text { Neoclassical } \\
\text { synthesis } \\
\text { model }\end{array}$ & $\begin{array}{l}\ln y=a_{0}-a_{1} r \quad \text { (IS) } \\
\ln \bar{M}-\ln P=b_{0}+b_{1} R-b_{2} \ln y \quad(\mathrm{LM}) \\
\ln y-\ln y^{*}=c_{0}+c_{1} \pi,(\mathrm{PC})\end{array}$ & ad hoc & Money supply & $\begin{array}{l}\text { Short-termdemand } \\
\text { management } \\
\text { Policy effectiveness in } \\
\text { short term } \\
\text { Policy ineffectiveness in } \\
\text { long term }\end{array}$ \\
\hline $\begin{array}{l}\text { Sargent-Wallace } \\
\text { model }\end{array}$ & $\begin{array}{l}\ln y_{t}=a_{0}-a_{1} r_{t} \quad(\mathrm{IS}) \\
\ln \bar{M}-\ln P_{t}=b_{0}+b_{1} R_{t}-b_{2} \ln y_{t} \quad(\mathrm{LM}) \\
\ln y_{t}=c_{0}+c_{1}\left(\ln P_{t}-E_{t-1} \ln P_{t}\right) \quad(\text { Lucas AS })\end{array}$ & ad hoc & Money supply & $\begin{array}{l}\text { Rational expectation } \\
\text { Policy ineffectiveness }\end{array}$ \\
\hline $\begin{array}{l}\text { IS-LM-NPC } \\
\text { Model }\end{array}$ & $\begin{array}{l}\ln y_{t}=a_{0}-a_{1} r_{t}+E_{t} \ln y_{t+1} \quad \text { (IS) } \\
\ln M_{t}-\ln P_{t}=b_{0}+b_{1} \ln y_{t}-b_{2} R_{t ?} \quad(\mathrm{LM}) \\
\ln y_{t}-\ln y_{t}^{*}=c_{0}+c_{1}\left(\pi_{t}-\beta E_{t} \pi_{t+1}\right) \quad(\mathrm{NPC}) \\
R_{t}=\mu_{0}+E_{t} \pi_{t+1}+\mu_{1}\left(\pi_{t}-\bar{\pi}\right)+\mu_{2}\left(\ln y_{t}-\ln y_{t}^{*}\right) \quad \text { (Taylor Rule) }\end{array}$ & Optimization & Interest rate & $\begin{array}{l}\text { Rational expectation } \\
\text { Policy effectiveness } \\
\text { Improve status of } \\
\text { monetary policy }\end{array}$ \\
\hline $\begin{array}{l}\text { IS-MP-NPC } \\
\text { Model }\end{array}$ & $\begin{array}{l}\ln y_{t}=a_{0}-a_{1} r_{t}+E_{t} \ln y_{t+1} \quad \text { (IS) } \\
\ln y_{t}-\ln y_{t}^{*}=c_{0}+c_{1}\left(\pi_{t}-b \pi_{t}^{e}\right) \quad(\mathrm{NPC}) \\
R_{t}=\mu_{0}+\pi_{t}^{e}+\mu_{1}\left(\pi_{t}-\bar{\pi}\right)+\mu_{2}\left(\ln y_{t}-\ln y_{t}^{*}\right) \quad \text { (Taylor Rule) }\end{array}$ & ad hoc & Interest rate & $\begin{array}{l}\text { Policy effectiveness } \\
\text { Improve status of } \\
\text { monetary policy }\end{array}$ \\
\hline
\end{tabular}

representative agent does not do better than its predecessor in terms of bearing Lucas critique.

Although monopolistic competition in the new model also has heterogeneous characteristic, it mainly uses representative agent method. It is obviously inconsistent with sufficient reality of its policy analysis. The principle interpretation it provides far exceeds policy suggestion it offers. Hoover [21] points out that representative agent model of seeking micro-foundation actually misunderstands Lucas critique. Lucas critique is far from that one draws wrong conclusion due to ignorance of expectation factor. Before Lucas, Marschak [22] foresaw that people would act as we predicted under stable policy environment. Lucas just provided a case under the changes in policy environment changes or unstable economy. We have no reason to consider representative agent avoids such situation. Representative agent only owns the characteristic that any realistic individual does not own. He is not realistic individual who can participate in optimization of micro-economy. A large number of researches such as Debreu-Sonnenschein-Manteltheorem in 1970s indicate except very special and unbelievable conditions, individual preference or technology is impossibly aggregated a function at macroscopic level. In fact, there is no cause to consider aggregate variables in macro-economy will behavior like those variables in micro-economy. Thus, introduction of rational expectation in traditional IS-LM model or IS-MP-NPC model is more proper.

IS-MP-NPC model has been widely applied in macroeconomics texts, such as Hall and Taylor [23], DeLong and Olney [24], Haul and Papell [25], as well as Taylor [26]. This model better complies with new reality of center bank regarding interest rate as monetary policy objective, so it is widely applied in policy research projects of universities and central bank.

However, for ad hoc model like IS-MP-NPC which lacks micro-foundation, it is always difficult for scholars to release. The problem is that whether "micro-foundation of macroeconomics" is a real question. Economics excessively pursues logic consistency. Thus, self-amusement misunderstanding may be easily caught in. If approximate prediction results can be obtained, is the simpler the model, the better?

\section{Defects in the Second Round of Modification}

Traditional IS-LM model obtains great success in conciseness and figurativeness, but severe challenges are put 
forward for traditional IS-LM model in the following aspects: disconnection of deeper research of macroeconomics and real world, lack of micro-foundation, short-term static nature and internal logic conflict.

Thus, as early as the end of 1970s and beginning of 1980s, the first round of modification for the traditional model started. Popular rational expectation was combined to make IS-LM dynamic. Since micro-foundation problem fails to be solved, school of rational expectation insists monetary neutrality and macroeconomic policy ineffectiveness proposition, the first round of modification fails to achieve great success.

Through the second round of modification since the later period of 1990s, we have obtained IS-LM-NPC and IS-MP-NPC model. In this modification, the great breakthrough has been made in theoretical and empirical study due to successful construction of mathematical form of micro-foundation or consideration of new change in monetary policy regulation goal. However, there still exist some limitations which can be hardly solved in new model, such as aggregate problem and representative agent assumption. Even though we relax the representative agent assumption into heterogeneous agent situation, the aggregate problem still can't be solved; on the contrary, the model will become more complicated, and it is hard to carry out mathematical processing. In the future research on IS-LM model in the academic circle, these problems must be taken into account. We think that the "micro-foundation of macro economics" may be unnecessary, and it is not a true problem. It is unnecessary for us to be entangled in establishing a micro-foundation for IS-LM model; however, we should focus on the setting of relationship of macroeconomic behavior and the discussion on consistency with empirical data.

\section{Acknowledgements}

Supported by Youth Project of National Social Science Funds (13CJL003), General Project of Humanities \&Social Science Planning under the Ministry of Education (12XJC790006), the Fundamental Research Funds for the Central Universities (SWU1309369).

\section{References}

[1] Dornbusch, R. and Fischer, S. (1984) Macroeconomics. 3rd Edition, McGraw-Hill, New York.

[2] Young, W. and Zilberfarb, B.Z. (2000) Introduction: Quo Vadis IS-LM? In: Young, W. and Zilberfarb, B.Z., Eds., IS-LM and Modern Macroeconomics, Kluwer Academic Publishers, 1-6. http://dx.doi.org/10.1007/978-94-010-0644-6_1

[3] Solow, R.Mr. (1984) Hicks and the Classics. Oxford Economic Papers, 36, 13-25.

[4] Lucas, R.E. (1976) Econometric Policy Evaluation: A Critique. In: Lucas, R.E., Ed., Studies in Business-Cycle Theory, MIT Press, Cambridge, 104-130. http://dx.doi.org/10.1016/S0167-2231(76)80003-6

[5] Hicks, J. (1945) La theorie de Keynes après neuf ans. Revue d'EconomiePolitique, 55, 1-11.

[6] Colander, D.C. (2004) The Strange Persistence of the IS-LM Model. History of Political Economy, 36, 305-322. http://dx.doi.org/10.1215/00182702-36-Suppl_1-305

[7] Vercelli, A. (1999) The Evolution of IS-LM Models: Empirical Evidence and Theoretical Presuppositions. Journal of Economic Methodology, 6, 199-219. http://dx.doi.org/10.1080/13501789900000014

[8] Chick, V. (1973) The Theory of Monetary Policy. Gray-Mills, London.

[9] Romer, D. (2000) Keynesian Macroeconomics without the LM Curve. The Journal of Economic Perspectives, 14, 149-169. http://dx.doi.org/10.1257/jep.14.2.149

[10] Walsh, C. (2002) Teaching Inflation Targeting: An Analysis for Intermediate Macro. Journal of Economic Education, 33, 333-346. http://dx.doi.org/10.1080/00220480209595331

[11] Sargent, T.J. and Wallace, N. (1975) "Rational” Expectations, the Optimal Monetary Instrument, and the Optimal Money Supply Rule. Journal of Political Economy, 83, 241-254. http://dx.doi.org/10.1086/260321

[12] Blanchard, O.J. (1981) Output, the Stock Market and Interest Rates. American Economic Review, 71, $132-143$.

[13] McCallum, B. (1989) Monetary Economics: Theory and Policy. Macmillan, New York.

[14] Koenig, E. (1993) Rethinking the IS in IS-LM: Adapting Keynesian Tools to Non-Keynesian Economics. Part 1. Federal Reserve Bank of Dallas Economic Review, 33-49.

[15] Auerbach, A. and Kotlikoff, L. (1995) Macroeconomics: An Integrated Approach. South-Western, Cincinnati.

[16] Bernanke, B. and Woodford, M. (1997) Inflation Forecasts and Monetary Policy. Journal of Money, Credit and Banking, 29, 653-684. http://dx.doi.org/10.2307/2953656

[17] McCallum, B. and Nelson, E. (1999) An Optimizing IS-LM Specification for Monetary Policy and Business Cycle 
Analysis. Journal of Money, Credit, and Banking, 31, 296-316. http://dx.doi.org/10.2307/2601113

[18] King, R. (2000) The New IS-LM Model: Language, Logic, and Limits. Economic Quarterly, Federal Reserve Bank of Richmond, 86, 45-103. http://ssrn.com/abstract=2126570

[19] Bofinger, P., Mayer, E. and Wollmershäuser, T. (2002) The BMW Model: Simple Macroeconomics for Closed and Open Economies-A Requiem for the IS/LM-AS/AD and the Mundell-Fleming Model. Wurzburg Economic Papers, 35, 1-86.

[20] Bofinger, P., Mayer, E. and Wollmershäuser, T. (2006) The BMW Model: A New Framework for Teaching Monetary Economics. The Journal of Economic Education, 37, 98-117. http://dx.doi.org/10.3200/JECE.37.1.98-117

[21] Hoover, K.D. (2006) A Neo-Wicksellian in a New Classical World: The Methodology of Michael Woodford's Interest and Prices. Journal of the History of Economic Thought, 28, 143-149. http://dx.doi.org/10.1080/10427710600676322

[22] Marschak, J. (1953) Economic Measurements for Policy and Predictions. In: Hood, W.C. and Koopmans, T.C., Eds., Studies in Econometric Method, Cowles Foundations Monographno No. 14, Wiley, New York.

[23] Haul, R.E. and Taylor, J.B. (2002) Macroeconomics. 5th Edition, China Renmin University Press, Beijing.

[24] DeLong, J. B. and Olney, M.L. (2006) Macroeconomics. 2nd Edition, McGraw-Hill, Inc., New York.

[25] Haul, R.E. and David, H.P. (2008) Macroeconomics. China Renmin University Press, Beijing.

[26] Taylor, J.B. (2007) Macroeconomics. 5th Edition, China Market Publishing House, Beijing. 